\title{
Прогнозирование величины захваченного заряда в захороненном оксиде кремния структур кремний-на-изоляторе с применением эфффекта Пула-Френкеля
}

\author{
(C) А.А. Ширяев ${ }^{1}$, В.М. Воротынцев ${ }^{2}$, Е.Л. Шоболов ${ }^{1}$ \\ ${ }^{1}$ Научно-исследовательский институт измерительных систем им. Ю.Е. Седакова, \\ 603137 Нижний Новгород, Россия \\ ${ }^{2}$ Нижегородский государственный технический университет им. Р.Е. Алексеева, \\ 603950 Нижний Новгород, Россия \\ E-mail: alsh92@rambler.ru
}

Поступила в Редакцию 2 декабря 2019 г.

В окончательной редакции 10 декабря 2019 г.

Принята к публикации 16 декабря 2019 г.

\begin{abstract}
Проведено исследование возможности прогнозирования с применением эффекта Пула-Френкеля величины захваченного заряда в захороненном оксиде кремния структур кремний-на-изоляторе. Путем измерения и моделирования вольт-амперных характеристик захороненного оксида кремния при разных температурах определены условия для эффекта Пула-Френкеля в этом слое. Рассмотрены процессы, протекающие в захороненном оксиде при измерении вольт-амперных характеристик и отжиге. Определены условия термополевой обработки захороненного оксида для имитации радиационного воздействия с помощью инжекции. Проведена оценка зависимости величины накопленного положительного заряда в захороненном оксиде кремния в результате инжекции от величины тока Пула-Френкеля. Показана возможность применения эффекта Пула-Френкеля для оценки дефектности захороненного оксида при изготовлении микросхем с повышенной дозовой радиационной стойкостью.
\end{abstract}

Ключевые слова: кремний-на-изоляторе, оксид кремния, эффект Пула-Френкеля, инжекция носителей заряда, радиационная стойкость.

DOI: 10.21883/FTP.2020.05.49256.9325

\section{1. Введение}

Одной из основных причин выхода из строя микросхем на основе комплементарной структуры металлоксид-полупроводник (КМОП), изготовленных с использованием структур кремний-на-изоляторе (КНИ), при воздействии ионизирующего излучения является накопление положительного заряда в захороненном оксиде кремния структуры КНИ. Этот процесс приводит к образованию паразитных проводящих каналов вдоль захороненного слоя оксида кремния и, как следствие, к повышению тока потребления микросхемы. Положительный заряд в захороненном оксиде образуется в результате захвата радиационно-индуцированных дырок на дефекты с глубокими уровнями в запрещенной зоне диоксида кремния. Таким образом, разработка методов контроля дефектности захороненного оксида и прогнозирования радиационной стойкости микросхем по результатам этого контроля является актуальной.

В работе [1] для исследования дефектности термического диоксида кремния был предложен метод на основе эффекта Пула-Френкеля. Метод заключается в определении концентрации и энергетического положения донорных центров диэлектрика путем сопоставления экспериментальной и теоретической вольт-амперных характеристик (BAX) диэлектрика, соответствующих механизму электропроводности Пула-Френкеля, при котором под действием электрического поля и температуры электроны эмитируются с донорных центров диэлектрика в зону проводимости диэлектрика. Целью настоящей работы являлась оценка возможности прогнозирования с применением эффекта Пула-Френкеля величины захваченного заряда в захороненном слое оксида структур кремний-на-изоляторе. В настоящей работе в качестве имитации радиационного воздействия применялась сильнополевая инжекция носителей заряда. Такой подход к имитации обоснован в работе [2]. Однако остается еще много нерешенных вопросов по его реализации, часть из которых рассматриваются в настоящей работе.

\section{2. Методика эксперимента}

Исследуемыми образцами являлись конденсаторы, образованные структурой КНИ. Нижней обкладкой конденсатора служила подложка p-типа проводимости, а верхней - карман $n$-типа в приборном слое структуры

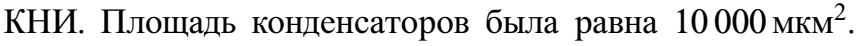
Толщина захороненного слоя оксида составляла 200 нм. Измерения проводились на 5 пластинах в 5 точках на каждой пластине. Использовались структуры КНИ, изготовленные по технологии Smart $\mathrm{Cut}^{\mathrm{TM}}$ [3].

Оценка дефектности захороненного оксида кремния проводилась методом на основе эффекта Пула-Френке- 
ля [1]. Для измерения BAX захороненного оксида использовались зондовая станция и измеритель параметров полупроводниковых приборов. Подложка структуры КНИ заземлялась. На $n$-карман подавалось напряжение от 0 до $-100 \mathrm{~B}$ с шагом 1 В. Измерялся ток $n$-кармана. Период импульса при измерении ВАХ составлял 104 мс, ширина импульса - 100 мс, задержка измерения после подачи импульса была 80 мс. ВАХ захороненного оксида измеряли в диапазоне температур от 295 до $473 \mathrm{~K}$. Для исследования влияния процесса измерения и отжига на проводимость Пула-Френкеля измерения ВАХ проводили многократно, после чего структура выдерживалась в течение 1 ч при температуре $473 \mathrm{~K}$. На основании измеренных ВАХ захороненного оксида рассчитывались зависимости плотности тока $J$ от напряженности поля $E$.

В качестве имитации радиационного воздействия использовался метод на основе инжекции носителей заряда $[2,4]$. Для осуществления инжекции использовались термополевые обработки (ТПО). При проведении ТПО подложка структуры КНИ заземлялась, на $n$-карман подавалось напряжение $-100 \mathrm{~B}$ (отрицательная термополевая обработка, ОТПО) или +100 В (положительная термополевая обработка, ПТПО). ТПО проводились в течение 5 мин при температуре $473 \mathrm{~K}$. Сначала проводилась ОТПО, затем ПТПО. Для оценки зарядового состояния захороненного оксида по напряжению плоских зон, $U_{f b}$, величина которого однозначно определяет концентрацию заряда в захороненном оксиде, до и после инжекции измерялись (при $473 \mathrm{~K}$ ) высокочастотные вольт-фарадные характеристики (ВФХ) структуры КНИ. Подложка структуры КНИ заземлялась. На $n$-карман подавалось напряжение от -20 В до +20 В с шагом $50 \mathrm{MB}$. Частота и амплитуда измерительного сигнала составляли 1 МГц и $10 \mathrm{MB}$ соответственно.

\section{3. Экспериментальные результаты}

На рис. 1 представлена экспериментальная зависимость плотности тока $J$ от напряженности электрического поля $E$ захороненного оксида и теоретическая зависимость, смоделированная по формулам, описывающим эффект Пула-Френкеля:

$$
\begin{gathered}
J=q \mu E N_{D}(T, E), \\
N_{D}=N_{C} \exp \left(-\frac{q \varphi-\sqrt{q^{3} E / \pi \varepsilon_{0} \varepsilon}}{k T}\right),
\end{gathered}
$$

где $q-$ элементарный заряд, $\mu-$ подвижность электронов в диэлектрике, $N_{D}(T, E)$ - концентрация ионизованных донорных центров в диэлектрике, $N_{C}-$ плотность квантовых состояний в зоне проводимости диэлектрика, $\varphi$ - энергия уровня донорных центров в диэлектрике (относительно дна зоны проводимости), $\varepsilon_{0}$ - электрическая постоянная, $\varepsilon$ - относительная диэлектрическая проницаемость диэлектрика, $k-$ постоянная Больцмана, $T$ - температура.

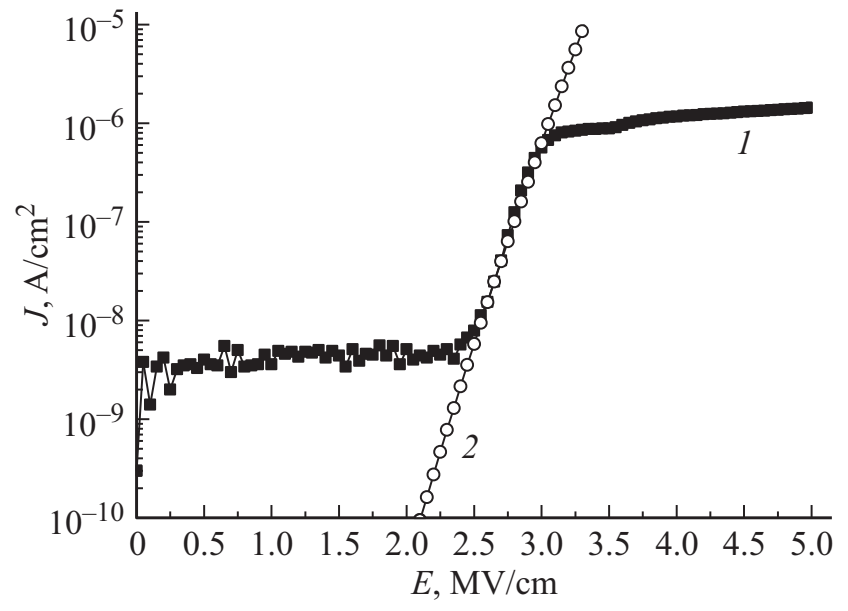

Рис. 1. Экспериментальная зависимость плотности тока $J$ от напряженности электрического поля $E$ захороненного слоя оксида кремния (1) и теоретическая зависимость (2), смоделированная по формулам (1) и (2), описывающим эффект Пула-Френкеля. Температура $295 \mathrm{~K}$.

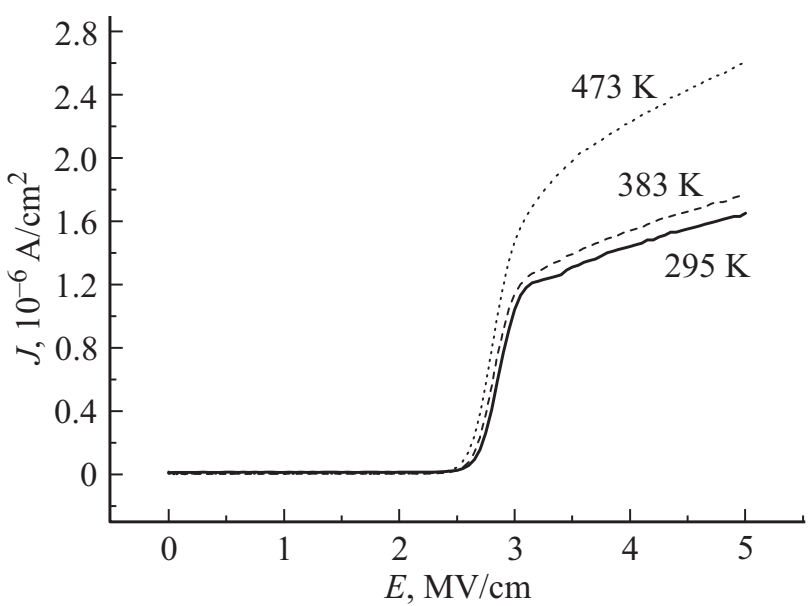

Рис. 2. Зависимости плотности тока от напряженности электрического поля для захороненного оксида кремния при разных температурах.

На рис. 2 приведены зависимости $J$ от $E$ захороненного оксида при разных температурах. Видно, что в диапазоне от комнатной температуры $(295 \mathrm{~K})$ до $473 \mathrm{~K}$ ток захороненного оксида несколько возрастает, но качественного изменения зависимостей $J$ от $E$ не происходит. Поэтому комнатной температуры достаточно для оценки дефектности захороненного оксида с помощью эффекта Пула-Френкеля.

На рис. 1 теоретическая зависимость, соответствующая эффекту Пула-Френкеля, хорошо согласуется с экспериментальной в диапазоне от 2.5 до $3 \mathrm{MB} / \mathrm{cm}$ при уровне донорных центров в захороненном оксиде 2.39 эВ ниже дна зоны проводимости. Концентрация донорных центров при комнатной температуре $(295 \mathrm{~K})$ и напряженности $3 \mathrm{MB} / \mathrm{cm}$ составила $6.53 \cdot 10^{4} \mathrm{~cm}^{-3}$. 
Следует отметить, что линейный характер зависимости $J$ от $E$ захороненного оксида в диапазоне от 3 до $5 \mathrm{MB} / \mathrm{cm}$ (рис. 2) свидетельствует о преобладании в этом диапазоне омического механизма электропроводности [5].

При проведении эксперимента было замечено, что качественное изменение зависимости $J$ от $E$ захороненного оксида происходит при ее повторном измерении (рис. 3). При этом после отжига форма зависимости восстанавливается.

Для имитации радиационного воздействия на захороненный оксид с помощью инжекции носителей заряда были проведены ТПО исследуемых образцов. На рис. 4 показаны участки высокочастотных $\mathrm{B} Ф \mathrm{X} C(U)$ структур КНИ, измеренных при температуре $473 \mathrm{~K}$ до ТПО и после ОТПО, ПТПО. Из рис. 4 видно, что после ОТПО характеристика смещается влево, что соответствует

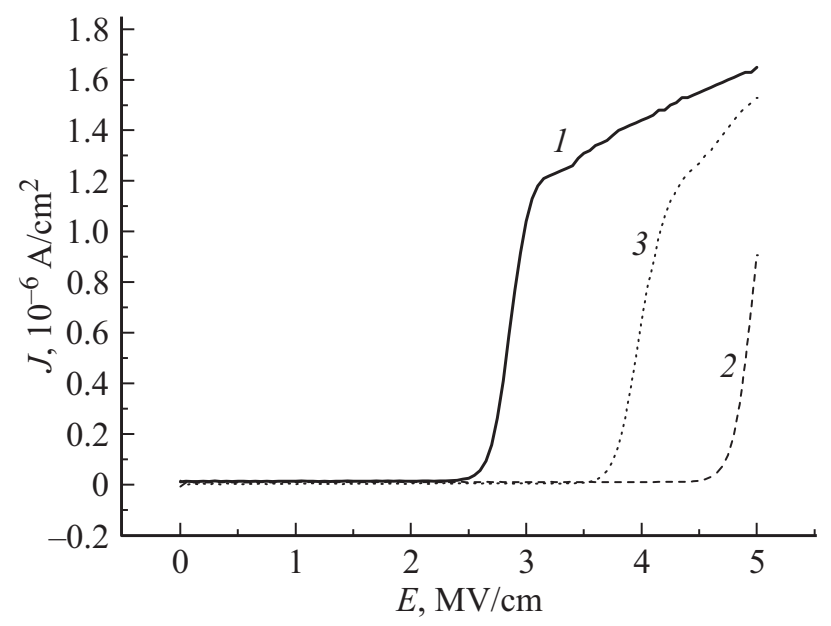

Рис. 3. Зависимости плотности тока от напряженности электрического поля для захороненного оксида, измеренные при $295 \mathrm{~K}$ первоначально (1), повторно (2) и после отжига (3).

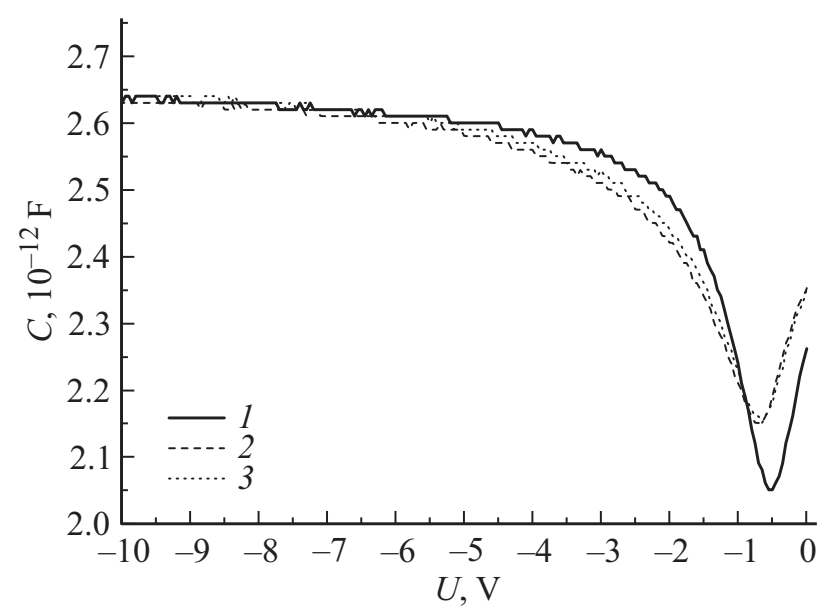

Рис. 4. Участки высокочастотных ВФХ структур КНИ, измеренных до ТПО (1), после ОТПО (2) и после ПТПО (3), проведенной сразу после ОТПО. Температура измерения $473 \mathrm{~K}$.

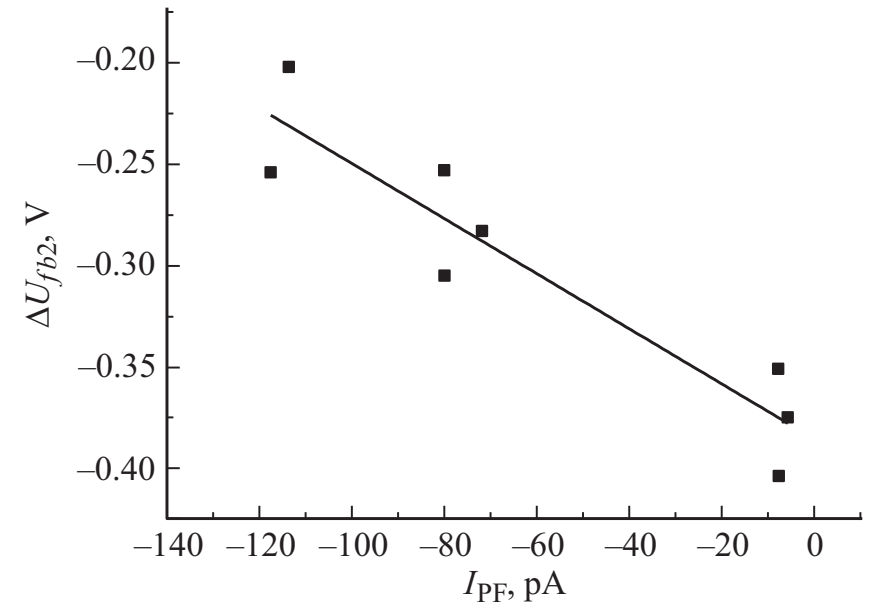

Рис. 5. Зависимость сдвига напряжения плоских зон структуры КНИ после суммарного воздействия ОТПО и ПТПО от тока Пула-Френкеля захороненного оксида (точки) и линейная аппроксимация (скорректированный коэффициент детерминации $\left.R_{\text {adj }}^{2}=0.84396\right)$.

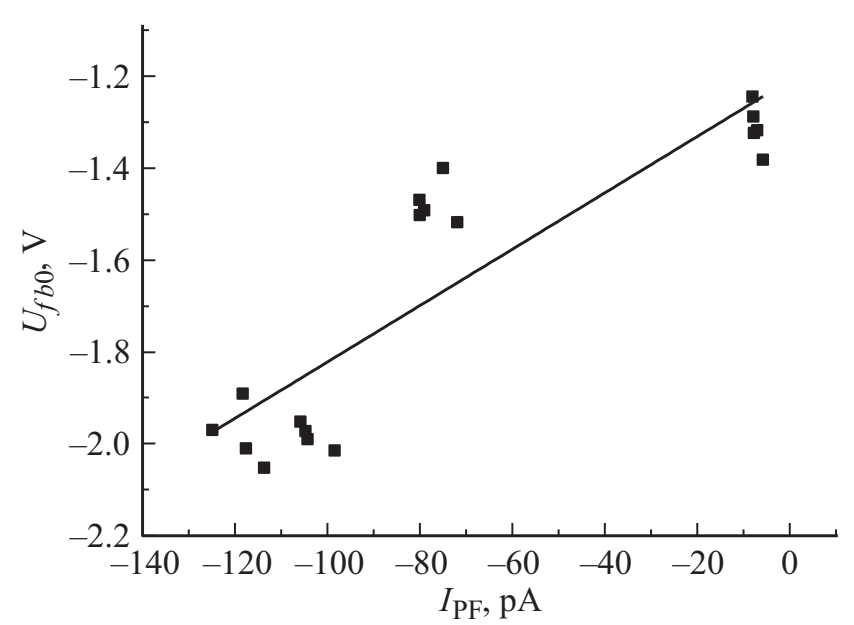

Рис. 6. Зависимость напряжения плоских зон структуры КНИ после измерения ВАХ захороненного оксида (до проведения ТПО) от тока Пула-Френкеля захороненного оксида (точки) и линейная аппроксимация (скорректированный коэффициент детерминации $\left.R_{\text {adj }}^{2}=0.76289\right)$.

аккумуляции положительного заряда в захороненном оксиде. Для того чтобы отделить процесс инжекции от процессов миграции подвижных ионов, после ОТПО была проведена ПТПО. Исходя из предположения, что при сильнополевой инжекции как электронов, так и дырок в захороненном оксиде накапливается положительный заряд [2], можно сделать вывод, что смещение высокочастотных ВФХ вправо после ПТПО связано с миграцией подвижных ионов. Таким образом, наиболее достоверные данные по имитации радиационного воздействия были получены после вычисления сдвига напряжения плоских зон в результате суммарного действия ОТПО и ПТПО. 
На рис. 5 представлена линейная аппроксимация (по методу наименьших квадратов) зависимости сдвига напряжения плоских зон структуры КНИ после суммарного действия ОТПО и ПТПО, $\Delta U_{f b 2}$, от тока Пула-Френкеля $I_{\mathrm{PF}}$, а на рис. 6 - линейная аппроксимация зависимости напряжения плоских зон структуры КНИ после измерения ВАХ (но до ТПО), $U_{f b 0}$, от $I_{\mathrm{PF}}$. На рис. 5 и 6 точки образуют группы, соответствующие разным пластинам. Линейная зависимость для аппроксимации выбрана в качестве исходной позиции для иллюстрации наличия зависимости. В пределах пластин зависимость не прослеживается; тем не менее использование нескольких измерений на каждой пластине позволило снизить влияние погрешности измерений на обнаружение зависимости при переходе от пластины к пластине.

Следует отметить, что скорректированный коэффициент детерминации $R_{\text {adj }}^{2}$ зависимости сдвига напряжения плоских зон после ОТПО $\Delta U_{f b 1}\left(I_{\mathrm{PF}}\right)$, не проиллюстрированной рисунком, оказался меньше, чем в случае зависимости $\Delta U_{f b 2}\left(I_{\mathrm{PF}}\right)$, и составил 0.78655 .

\section{4. Обсуждение полученных результатов}

В настоящей работе путем сопоставления экспериментальной и теоретической зависимостей плотности тока $J$ захороненного оксида от напряженности поля $E$ было установлено, что эффект Пула-Френкеля в захороненном оксиде наблюдается при комнатной температуре в диапазоне напряженности от 2.5 до $3 \mathrm{MB} / \mathrm{cm}$ (рис. 1 и 2). При этом хорошее согласие результатов моделирования и измерений соответствует уровню донорных центров в захороненном оксиде, лежащему на 2.39 эВ ниже дна зоны проводимости, что хорошо согласуется с данными работ $[1,4]$. Однако в работах $[1,4]$ эффект Пула-Френкеля в подзатворном оксиде кремния наблюдался в диапазоне от 6 до $10 \mathrm{MB} / \mathrm{cm}$. Различие диапазона напряженности, соответствующего эффекту Пула-Френкеля, в случае захороненного оксида и в случае подзатворного оксида кремния, по всей видимости, связано с технологией получения слоев. Подзатворный оксид кремния в работах $[1,4]$ был получен влажным окислением, а захороненный оксид в образцах структур КНИ, исследуемых в настоящей работе, был получен комбинацией сухого и влажного окисления в рамках технологии Smart $\mathrm{Cut}^{\mathrm{TM}}$. В процессе роста влажного оксида ОН-группы гидролизуют кислородные вакансии [6]. Таким образом, концентрация вакансий кислорода, которые, согласно [7], являются основными донорными центрами в диоксиде кремния, в захороненном оксиде выше, чем в подзатворном, что, повидимому, и оказывает влияние на диапазон напряженности, соответствующий эффекту Пула-Френкеля. Это предположение подтверждается литературными данными. В работе [8] исследовались захороненный слой оксида кремния толщиной 400 нм, полученный имплантацией кислорода и, следовательно, имеющий высокую концентрацию вакансий кислорода, и термический оксид кремния той же толщины, выращенный в парах воды, в котором концентрация вакансий кислорода мала. При этом в работе [8] эффект Пула-Френкеля в захороненном оксиде наблюдался в диапазоне напряженности от 2.25 до $4 \mathrm{MB} / \mathrm{cm}$, а в термическом оксиде рост тока, по-видимому, связанный с эффектом Пула-Френкеля, начинался при превышении напряженности $5 \mathrm{MB} / \mathrm{cm}$. В настоящей работе предполагается, что при имитации радиационного воздействия с помощью инжекции не происходит образования новых вакансий кислорода за счет освобождения ОН-групп.

Наличие участка омической проводимости, а также качественное изменение зависимости $J$ от $E$ захороненного оксида при повторном измерении (рис. 3) и ее восстановление после отжига можно объяснить следующим образом. В процессе измерения ВАХ захороненного оксида в диапазоне от 2.5 до $3 \mathrm{MB} / \mathrm{cm}$, как уже было сказано, имеет место эффект Пула-Френкеля. При напряженности $3 \mathrm{MB} / \mathrm{cm}$ все донорные центры, участвующие в проводимости Пула-Френкеля, оказываются ионизованными. Поэтому при дальнейшем увеличении напряжения проводимость осуществляется только за счет электронов в зоне проводимости диэлектрика, появившихся там вследствие ионизации донорных центров. Поэтому в диапазоне от 3 до $5 \mathrm{MB} / \mathrm{cm}$ проводимость подчиняется закону Ома. После окончания измерения BAX электроны вследствие их высокой подвижности переходят из захороненного оксида в кремний, а донорные центры захороненного оксида остаются ионизованными. Поэтому при повторном измерении ВАХ захороненного оксида ток начинает расти только при напряженности $4.5 \mathrm{MB} / \mathrm{cm}$ (рис. 3), но (поскольку все донорные центры уже ионизованы) уже не по механизму Пула-Френкеля, а по механизму Фаулера-Нордгейма [5] (сильнополевой инжекции заряда). В свою очередь высокотемпературный отжиг способствует нейтрализации донорных центров диэлектрика и восстановлению формы зависимости $J$ от $E$.

Следует отметить, что это доказывает справедливость выбора режимов термополевых обработок, соответствующих длительной выдержке при напряженности $5 \mathrm{MB} / \mathrm{cm}$ и, следовательно, сопровождающихся сильнополевой инжекцией Фаулера-Нордгейма. В разд. 3 было установлено, что для отделения процесса инжекции носителей заряда от процесса миграции подвижных ионов в захороненном оксиде при имитации радиационного воздействия по методу инжекции следует применять последовательно отрицательную и положительную термополевые обработки. Этот вывод подкрепляется тем, что коэффициент детерминации зависимости сдвига напряжения плоских зон после суммарного действия ОТПО и ПТПО, $\Delta U_{f b 2}\left(I_{\mathrm{PF}}\right)$, оказался выше, чем в случае зависимости сдвига напряжения плоских зон после ОТПО, $\Delta U_{f b 1}\left(I_{\mathrm{PF}}\right)$. 
В результате анализа корреляции тока Пула-Френкеля, $I_{\mathrm{PF}}$, и сдвига напряжения плоских зон после имитации радиационного воздействия с помощью инжекции, $\Delta U_{f b 2}$, были сделаны следующие выводы. Из рис. 5 видно, что между этими величинами есть зависимость. Однако она является убывающей, и это факт, противоречащий предположению о том, что высокая дефектность захороненного оксида, об уровне которой свидетельствует высокий ток (по модулю) $I_{\mathrm{PF}}$, приводит к высокой концентрации захваченного положительного заряда после воздействия ионизирующего излучения или его имитации. По-видимому, причина в том, что имитация радиационного воздействия проводилась на тех же самых структурах, на которых предварительно проводилось измерение ВАХ захороненного оксида. Как уже было сказано, после первого измерения зависимость $J(E)$ качественно меняется (рис. 3), что объясняется зарядкой донорных центров захороненного оксида. Из рис. 6 видно, что существует возрастающая зависимость напряжения плоских зон, измеренного до инжекции (но после измерения ВАХ), от величины $I_{\mathrm{PF}}$. Следовательно, чем выше ток при измерении ВАХ, тем больше заряда накапливается в захороненном оксиде до инжекции и тем меньше заряда накапливается в оксиде в процессе инжекции, т.е. чем больше донорных центров в захороненном оксиде оказывается ионизовано после измерения ВАХ, тем меньше останется донорных центров, способных зарядиться в процессе инжекции. Таким образом, протекание тока Пула-Френкеля в захороненном оксиде способствует меньшему накоплению заряда в захороненном оксиде в результате инжекции.

Наличие зависимости величины заряда в захороненном оксиде структур КНИ от протекания тока ПулаФренкеля говорит о том, что метод на основе эффекта Пула-Френкеля позволяет определять концентрацию центров в диэлектрике, способных захватывать положительный заряд, и, следовательно, может применяться для оценки дефектности захороненного оксида при изготовлении микросхем с повышенной дозовой радиационной стойкостью.

\section{5. Заключение}

В настоящей работе проведено исследование возможности прогнозирования с применением эффекта ПулаФренкеля величины заряда, захваченного в захороненном оксиде в результате инжекции. Показано, что эффект Пула-Френкеля в захороненном оксиде проявляется при комнатной температуре в диапазоне напряженности электрического поля от 2.5 до $3 \mathrm{MB} / \mathrm{cm}$. Рассмотрены процессы, протекающие в захороненном оксиде при измерении ВАХ захороненного оксида и отжиге. Установлено, что проведение инжекции с помощью двух термополевых обработок (сначала отрицательной, затем положительной) позволяет отделить процесс инжекции носителей заряда от миграции подвижных ионов при имитации радиационного воздействия на захороненный оксид. Показано наличие зависимости величины заряда от величины тока Пула-Френкеля в захороненном оксиде структур КНИ, свидетельствующей о возможности применения эффекта Пула-Френкеля для оценки дефектности захороненного оксида при изготовлении микросхем с повышенной дозовой радиационной стойкостью.

\section{Конфликт интересов}

Авторы заявляют, что у них нет конфликта интересов.

\section{Список литературы}

[1] А.А. Ширяев, В.М. Воротынцев, Е.Л. Шоболов. ФТП, 52 (9), 990 (2018).

[2] M. Knoll, D. Braunig, W.R. Fahrner. J. Appl. Phys., 53 (10), 6946 (1982).

[3] G.K. Celler, S. Cristoloveanu. J. Appl. Phys., 93 (9), 4955 (2003).

[4] А.А. Ширяев, В.М. Воротынцев, Е.Л. Шоболов. Электрон. техн., сер. 2. Полупроводниковые приборы, 3 (254), 29 (2019).

[5] F.C. Chiu. Adv. Mater. Sci. Engin., 2014, 578168 (2014).

[6] R.A.B. Devine. Nucl. Instr. Meth. Phys. Res., Section B: Beam Interactions with Materials and Atoms, 46 (1-4), 244 (1990).

[7] S.T. Pantelides, Z.-Y. Lu, C. Nicklaw, T. Bakos, S.N. Rashkeev, D.M. Fleetwood, R.D. Schrimpf. J. Non-Cryst. Solids, 354, 217 (2008).

[8] A.G. Revesz, G.A. Brown, H.L. Hughes. J. Electrochem. Soc., 140 (11), 3222 (1993).

Редактор Л.В. Шаронова

\section{Prediction of trapped charge value in buried silicon oxide of silicon-on-insulator structures using Poole-Frenkel effect}

\author{
A.A. Shiryaev ${ }^{1}$, V.M. Vorotyntsev ${ }^{2}$, E.L. Shobolov ${ }^{1}$ \\ ${ }^{1}$ Sedakov Scientific Research Institute \\ of Measurment Systems, \\ 603137 Nizhny Novgorod, Russia \\ ${ }^{2}$ Alekseev Nizhny Novgorod State Technical University, \\ 603950 Nizhny Novgorod, Russia
}

\begin{abstract}
The opportunity to predict trapped charge value in buried silicon oxide of silicon-on-insulator structures using Poole-Frenkel effect was investigated. Using measuring and modeling of current-voltage characteristics of buried silicon oxide at different temperatures conditions for Poole-Frenkel effect in this layer were determined. Processes taking place in buried oxide during measurement of current-voltage characteristics and annealing were considered. Conditions of thermal field treatment of buried oxide for radiation exposure imitation using injection were determined. Dependence of accumulated positive charge value in buried silicon oxide as a result of injection on Poole-Frenkel current value was estimated. The opportunity to use Poole-Frenkel effect for buried oxide defectiveness evaluation during manufacturing of microcircuits with enhanced dose radiation hardness is shown.
\end{abstract}

